\title{
In situ detection of subsurface biofilm using low-field NMR: A field study
}

\author{
Authors: Catherine M. Kirkland, Maria P. Herrling, \\ Randy Hiebert, Andrew T. Bender, Elliot Grunewald, \\ David O. Walsh, \& Sarah L. Codd
}

NOTICE: This document is the unedited author's version of a Submitted Work that was subsequently accepted for publication in Environmental Science \& Technology, copyright (C) American Chemical Society after peer review. To access the final edited and published work, see http://dx.doi.org/10.1021/acs.est.5b02690.

Kirkland CM, Herrling MP, Hiebert R, Bender AT, Grunewald E, Walsh DO, Codd SL, "In situ detection of subsurface biofilm using low-field NMR: A field study," Environmental Science \& Technology 2015 Sep 15 49(18):11045-52. 


\title{
In Situ Detection of Subsurface Biofilm Using Low-Field NMR: A Field Study
}

\author{
Catherine M. Kirkland, ${ }^{\dagger}+$ Maria P. Herrling, $^{\S}$ Randy Hiebert ${ }^{\dagger}$ Andrew T. Bender, ${ }^{\dagger}, \|$ \\ Elliot Grunewald, ${ }^{\perp}$ David O. Walsh, ${ }^{\perp}$ and Sarah L. Codd*, ${ }^{\dagger}, \uparrow$ \\ ${ }^{\dagger}$ Center for Biofilm Engineering, Montana State University, Bozeman, Montana 59717, United States \\ \$Department of Chemical and Biological Engineering, Montana State University, Bozeman, Montana 59717, United States \\ $\S$ \\ Chair of Water Chemistry and Water Technology, Karlsruhe Institute of Technology, Karlsruhe 76131, Germany \\ "Department of Mechanical and Industrial Engineering, Montana State University, Bozeman, Montana 59717, United States \\ ${ }^{\perp}$ Vista Clara Inc., 12201 Cyrus Way Ste. 104, Mukilteo, Washington 98275, United States
}

ABSTRACT:

Subsurface biofilms are central to bioremedia-tion of chemical contaminants in soil and groundwater whereby microorganisms degrade or sequester environmental pollutants like nitrate, hydrocarbons, chlorinated solvents and heavy metals. Current methods to monitor subsurface biofilm growth in situ are indirect. Previous laboratory research conducted at MSU has indicated that low-field nuclear magnetic resonance (NMR) is sensitive to biofilm growth in porous media, where biofilm contributes a polymer gel-like phase and enhances T2 relaxation. Here we show that a small diameter NMR well logging tool can detect biofilm accumulation in the subsurface using the change in T2 relaxation behavior over time. T2 relaxation distributions were measured over an 18 day experimental period by two NMR probes, operating at approximately $275 \mathrm{kHz}$ and $400 \mathrm{kHz}$, installed in $10.2 \mathrm{~cm}$ wells in an engineered field testing site. The mean $\log \mathrm{T} 2$ relaxation times were reduced by $62 \%$ and $43 \%$, respectively, while biofilm was cultivated in the soil surrounding each well. Biofilm growth was confirmed by bleaching and flushing the wells and observing the NMR signal's return to baseline. This result provides a direct and noninvasive method to spatiotemporally monitor biofilm accumulation in the subsurface.

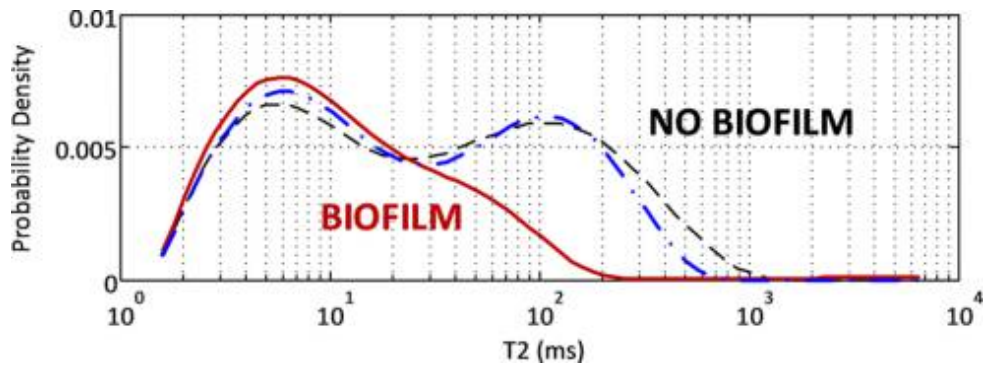

\section{INTRODUCTION:}

Reactive biofilm barriers, composed of attached microbial cells, extracellular polymeric substances (EPS), and entangled organic and inorganic molecules, can be cultivated in the subsurface to degrade and immobilize chemical contaminants as part of a bioremediation project. ${ }^{1}$ Contaminants in the groundwater, including nitrates, heavy metals, hydrocarbons, and some chlorinated solvents, are consumed or transformed by bacteria attached to soil surfaces while the EPS matrix slows the groundwater flow by reducing the soil's hydraulic conductivity. ${ }^{2-7}$ Although biobarrier technology is well-established to clean contaminated groundwater, 8,9 it is challenging with current technology to monitor the in situ accumulation and maturation of the biofilm nondestructively. Conventional methods to infer biofilm

growth in the subsurface include reduced saturated hydraulic conductivity, $10-12$ Although hydraulic conductivity measurements can be useful for describing how easily the soil conveys water, they are less useful for monitoring the growth, maturation, and decay of the biobarrier with spatial and temporal resolution. We present results indicating a small diameter nuclear magnetic resonance (NMR) well-logging tool provides addi-tional means of monitoring biofilm accumulation and conditionover time in the subsurface by detecting changes in the NMR signal response. Chemical and physical changes in a sample can impact a wide range of NMR parameters, including NMR frequency shifts, NMR relaxation times T1 and T2, and diffusion coefficients.13 NMR frequency shifts are typically caused by chemical changes in the fluid sample. However, at very low magnetic fields $(<1 \mathrm{MHz})$ even large proton chemical shifts such as those between oil and water are not detectable. Diffusion coefficients require additional magnetic field gradient hardware for detection, but can be used to distinguish different viscosity fluids in a sample or determine the average pore size of a material by measuring the time scale of the restricted diffusion. 9 NMR relaxation, $\mathrm{T} 1$ and $\mathrm{T} 2$, is caused by the correlation time of the diffusing fluid with respect to the resonant frequency of the NMR signal, as well as paramagnetic molecules the fluid comes into contact with. For these reasons, NMR relaxation times are affected by pore size distributions, fluid viscosity, and chemical changes in the mineralogy of any 
Table 1. Experiment Overview

\begin{tabular}{|c|c|c|}
\hline day & experimental task & purpose \\
\hline$(-2)-(-1)$ & $\begin{array}{l}\text { site preparation } \\
\text { injection of } 75-115 \mathrm{~L} \text { of sodium dichlor } \\
\text { concentrate solution } \\
\text { flush with test cell groundwater at } 45.5 \mathrm{~L} / \mathrm{min}\end{array}$ & create a "biofilm-free" initial condition \\
\hline 0 & $\begin{array}{l}\text { well logs } \\
T_{2} \text { distributions measured in } 0.5 \mathrm{~m} \text { increments over } \\
\text { the bottom } 3-3.5 \mathrm{~m} \text { saturated well depth }\end{array}$ & measure baseline $T_{2}$ distribution as a function of depth \\
\hline 1 & $\begin{array}{l}\text { inoculation } \\
\text { injection of } 30 \mathrm{~L} \text { inoculum culture of Pseudomonas } \\
\text { fluorescens CPC } 211 \text { a into measurement zone } \\
\text { surrounding the NMR probe at well bottom }\end{array}$ & promote attachment and biofilm formation by target organism \\
\hline $2-10$ & $\begin{array}{l}T_{2} \text { measurement in fixed location at well bottom } \\
\text { biofilm growth phase } \\
\text { injection of } 380-415 \mathrm{~L} \text { of molasses-based substrate } \\
\text { daily at } 1.2 \mathrm{~L} / \mathrm{min} \\
\text { measurements of } T_{2} \text { relaxation distributions daily in } \\
\text { fixed location at well bottom }\end{array}$ & $\begin{array}{l}\text { measure baseline } T_{2} \text { distribution at the well bottom } \\
\text { promote and measure biofilm accumulation }\end{array}$ \\
\hline $11-14$ & $\begin{array}{l}\text { starvation phase } \\
\text { measurements of } T_{2} \text { relaxation distributions Days } \\
12 \text { and } 14 \text { at the well bottom }\end{array}$ & $\begin{array}{l}\text { monitor biofilm resilience } \\
\text { establish "initial condition" to assess signal variation due to probe relocation }\end{array}$ \\
\hline 12 & $\begin{array}{l}\text { well logs } \\
T_{2} \text { distributions measured in } 0.5 \mathrm{~m} \text { increments over } \\
\text { the bottom } 3-3.5 \mathrm{~m} \text { saturated well depth }\end{array}$ & $\begin{array}{l}\text { measure } T_{2} \text { distribution as a function of depth after biofilm growth } \\
\text { evaluate signal variation due to probe relocation }\end{array}$ \\
\hline 14 & $\begin{array}{l}\text { biofilm stress tests } \\
\text { flush with test cell groundwater at } 45.5 \mathrm{~L} / \mathrm{min} \\
\text { injection of } 75-115 \mathrm{~L} \text { sodium dichlor concentrate } \\
\text { solution } \\
\text { measurements of } T_{2} \text { relaxation distributions in fixed } \\
\text { location at well bottom }\end{array}$ & monitor signal response to stresses intended to destroy biofilm \\
\hline 15 & $\begin{array}{l}\text { measurement of final conditions } \\
\text { flush with test cell groundwater at } 45.5 \mathrm{~L} / \mathrm{min} \\
\text { measurements of } T_{2} \text { relaxation distributions in fixed } \\
\text { location at well bottom }\end{array}$ & verify biofilm accumulation by signal restoration after detachment and removal of biofilm \\
\hline
\end{tabular}

solid matrix or dissolved ions. Measuring $T_{2}$ is significantly faster than measuring $T_{1} \cdot T_{2}$ measurements are generally considered the most robust low field measurement considering acquisition times and signal-to-noise.

In a $T_{2}$ measurement, the induced NMR signal echoes decay at a rate of $1 / T_{2}$, where $T_{2}$ is the spin-spin relaxation time associated with interactions in the fluid-pore environment. Analyzing the signal decay curve with the inverse Laplace transform produces a statistical distribution of $T_{2}$ relaxation times that reflect the variety of pore-scale environments occupied by hydrogen protons in the excitation shell. The $T_{2}$ relaxation time distribution in heterogeneous porous media is used, both in hydrogeologic analysis ${ }^{14}$ and in oil and gas exploration, ${ }^{15-18}$ to estimate the pore size distribution in the formation and for fluid typing. ${ }^{9}$ Biofilm accumulation in pores causes $T_{2}$ relaxation times to decrease compared to unclogged pores as the biofilm EPS contributes a biopolymer gel-like phase. ${ }^{19,20}$ Water in the EPS matrix contributes a reduced NMR relaxation signal $^{21}$ and demonstrates restricted diffusion. ${ }^{22}$

The NMR well-logging tool used in this study measures $T_{2}$ relaxation and was designed for use in small diameter "slimline" boreholes for groundwater exploration and aquifer characterization. ${ }^{14}$ In preliminary work, it was shown that this NMR logging tool can detect biofilm growth. ${ }^{20}$ The tool was tested in a laboratory-scale model well-bore bioreactor filled with silica sand and inoculated with Bacillus mojavensis. Biofilm was cultivated in the reactor over 8 days, during which the measured mean $\log T_{2}$ relaxation time decreased by $45 \%$, from 710 to $389 \mathrm{~ms}^{20}$ Biofilm accumulation was confirmed with destructive sampling and subsequent heterotrophic plate counts and microscopy. The current research significantly advances previous work by showing that the same logging tool can monitor biofilm growth at field scale, $6 \mathrm{~m}$ underground where complex water chemical interactions exist. The NMR tool could be deployed to bioremediation sites in parallel with currently used methods to enhance the understanding of biofilm growth in situ.

\section{MATERIALS AND METHODS}

This study used two $8.9 \mathrm{~cm}$ diameter, $1.37 \mathrm{~m}$ long NMR welllogging probes (JP350 Javelin by Vista Clara, Inc., Mukilteo, WA) to monitor $T_{2}$ relaxation distributions over time as an indication of biofilm accumulation in the soil in an engineered test cell. The test cell is $55 \mathrm{~m}$ by $40 \mathrm{~m}$ at the surface and is $6 \mathrm{~m}$ deep with $2: 1$ side slopes $(x: z)$. The cell is lined with a $30 \mathrm{~mm}$ polyvinyl chloride (PVC) liner and contains water up to $1-1.2$ $\mathrm{m}$ beneath the ground surface. The test cell contains a number of boreholes of varying dimensions that were prepared for a previous experiment. ${ }^{7}$ Two of the $10.2 \mathrm{~cm}$ boreholes were used for measurements of $T_{2}$ relaxation over an 18 day experimental period.

A bleach solution consisting of $2 \mathrm{lb}(907 \mathrm{~g})$ of sodium dichloro-s-triazinetrione dihydrate $\left(\mathrm{C}_{3} \mathrm{H}_{4} \mathrm{Cl}_{2} \mathrm{~N}_{3} \mathrm{NaO}_{5}\right)$ (Spa Guard Chlorinating Concentrate, Bio-Lab Inc., Lawrenceville, GA) was pumped into the soil around the two wells at the beginning and end of the experiment. A $30 \mathrm{~L}$ inoculum of Pseudomonas fluorescens strain CPC211a was injected into each well's measurement zone and was cultivated with a pulsed flow 
of molasses-based substrate $(10 \mathrm{~g} / \mathrm{L}$ molasses (Aunt Patty's Blackstrap Molasses, Eugene, OR), 3 g/L sodium nitrate (SQM industrial grade prills, 98\%, SQM North America, Atlanta, GA), $1 \mathrm{~g} / \mathrm{L}$ yeast extract (Acros Organics, Geel, Belgium), $0.12 \mathrm{~g} / \mathrm{L}$ potassium phosphate dibasic, and $0.04 \mathrm{~g} / \mathrm{L}$ potassium phosphate monobasic (Thermo-Fisher Scientific, Waltham, MA)) for 10 days. A 4 day starvation period followed the growth phase. $T_{2}$ measurements were conducted at the well bottom daily during the growth phase, Days $1-10$, and twice during the starvation phase, Days 12 and 14. Water samples were collected prior to $T_{2}$ experiments for subsequent $\mathrm{pH}$ measurement and microbial analysis using the drop plate method. ${ }^{23} T_{2}$ relaxation measurements were also recorded over the bottom 3-3.5 m of well depth twice during the experiment; wells were logged before inoculation and during the starvation period. At the end of the experiment, the sodium dichlor bleach solution and high groundwater flows were applied to the experimental region as a validation of biofilm growth, since these stress tests would be expected to remove EPS formed during the growth phase. The experiment was designed to distinguish normal variation in signal response due to environmental noise and probe placement from those changes resulting from biological activity and biofilm growth. The experimental sequence of events for a single well is shown in Table 1; both wells received identical treatment. Additional details regarding experimental methods are provided in the Supporting Information.

The two NMR probes were tuned to different frequencies, corresponding to excitation shells at a different radii from the well centers. The lower frequency probe (LF) was placed in one well, called the LF well, and was tuned to 245 and $290 \mathrm{kHz}$. Two excitation shells $0.5 \mathrm{~m}$ in height and a few mm thick were located 17-19 cm from the LF well center. The higher frequency probe (HF), installed in the HF well, was tuned to 360 and $425 \mathrm{kHz}$, producing two excitation shells located 11$13 \mathrm{~cm}$ from the HF well center. The probes are identical lowfield NMR tools other than the tuning frequency.

A diverter disk attachment was connected to the top of each probe to direct the substrate and high flows of water into the soil around the well-bore, rather than into the water column above the probe. A millimeter-scale gap was left between the disk and the well casing to ensure that the probe could be removed from the well. The disk was machined with an attachment for a standard garden hose to accommodate high volume flushing and four $0.1 \mathrm{~cm}$ holes for low-flow nutrient tubing (Figure 1). Pore velocity during the substrate injection was approximately $0.2 \mathrm{~cm} / \mathrm{min}$ in the LF well and $0.4 \mathrm{~cm} / \mathrm{min}$ in the HF well each probe's sensitive zone. The high volume flush created a pore velocity of approximately $9.2 \mathrm{~cm} / \mathrm{min}$ in the LF well and $14.8 \mathrm{~cm} / \mathrm{min}$ in the HF well.

For each probe, Experiments 1 and 2 (Table 2) constitute one standard Carr-Purcell-Meiboom-Gill (CPMG) $)^{24,25}$ measurement of approximately $27 \mathrm{~min}$. This standard measurement was conducted 4 times in each well for a typical wellbottom measurement of approximately $2 \mathrm{~h}$ Days 0-15, excluding Days 11 and 13. The data was averaged to obtain a single measurement for each day for each well. This standard measurement was also used at each $0.5 \mathrm{~m}$ depth increment when vertically logging the wells before and after biofilm growth on Day -1 and Day 12. An additional 12 standard measurements were made in one or the other well on alternating days to improve the signal-to-noise ratio in the

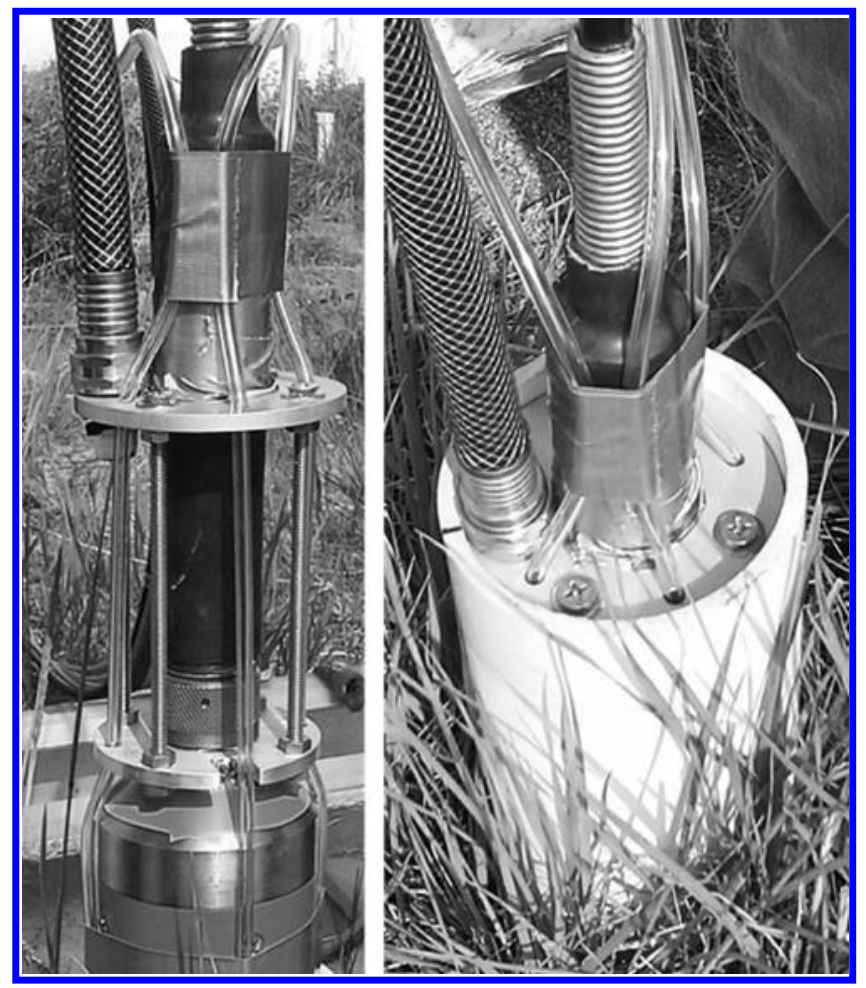

Figure 1. Diverter disk attachment on the top of each NMR logging tool directed substrate and high flow groundwater flushes into the biofilm growth region in the tool's sensitive zone in the soil and reduced backflow up the well casing.

\section{Table 2. NMR Experimental Parameters}

\begin{tabular}{lllllll} 
& \multicolumn{2}{c}{ LF probe } & & \multicolumn{2}{c}{ HF probe } \\
\cline { 2 - 3 } \cline { 5 - 6 } & Expt 1 & Expt 2 & & Expt 1 & Expt 2 \\
echo time, $t_{\mathrm{E}}(\mathrm{ms})$ & 1.5 & 1.5 & & 1.3 & 1.3 \\
repetition time, $T_{\mathrm{r}}(\mathrm{ms})$ & 1500 & 5000 & & 1500 & 5000 \\
acquisition time $(\mathrm{ms})$ & 50 & 500 & & 50 & 500 \\
no. of echoes & 34 & 334 & & 39 & 385 \\
no. of averages & 600 & 150 & & 600 & 150 \\
\hline
\end{tabular}

data collected and to confirm that 4 measurements was adequate to describe the system.

\section{RESULTS AND DISCUSSION}

Both the LF and HF NMR logging probes recorded changing distributions of $T_{2}$ relaxation times during the experiment with reductions of $62 \%$ and $43 \%$, respectively, in the mean $\log T_{2}$ during the biofilm growth phase (Figure 2). In the LF well, the $T_{2}$ relaxation time was $29 \mathrm{~ms}$ on Day 1 and fell to an average of $11 \mathrm{~ms}$ between Days 5 and 12 . Over the same period, the HF well $T_{2}$ relaxation time fell from $50 \mathrm{~ms}$ to an average of $28 \mathrm{~ms}$. Data from both wells initially showed a $T_{2}$ distribution with two peaks that transitioned to a single peak distribution by Day 6 (Figure 3a,b).

In the Day 1 data, the relaxation time distribution is bimodal. Given that there was only one fluid type at this time, the relaxation distribution peaks represent the relative pore size distribution. Water in the smaller pores relaxes more quickly due to the higher $\mathrm{S} / \mathrm{V}$ ratio and the more frequent interactions of the diffusing fluid molecules with the grain surfaces. ${ }^{26}$ Water in the larger pores experiences fewer interactions on the measurement time scale and yields slower signal decay. 


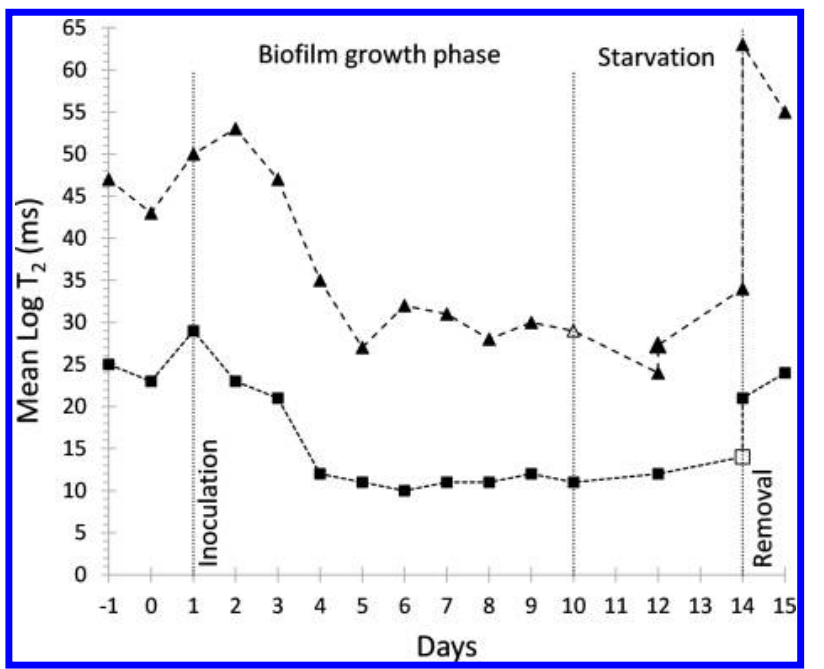

Figure 2. Mean $\log T_{2}$. Mean $\log T_{2}$ relaxation times decreased $62 \%$ (LF) and $43 \%$ (HF) indicating that protons became more rotationally constrained as biofilm was cultivated in the soil (LF well data is shown with square markers, HF well data with triangle markers). The first measurements were performed on Day -1 after bleaching and flushing both wells. Inoculation occurred on Day 1 . Substrate was injected daily Days 2-10. Days 11-14, the bacteria were starved. On Day 14, $T_{2}$ relaxation was measured, then the wells were flushed with high flows of groundwater from the test cell and $T_{2}$ was measured again. Then a bleach solution was injected to oxidize remaining organics. Day 15 data was collected after flushing the bleach solution from the wells.
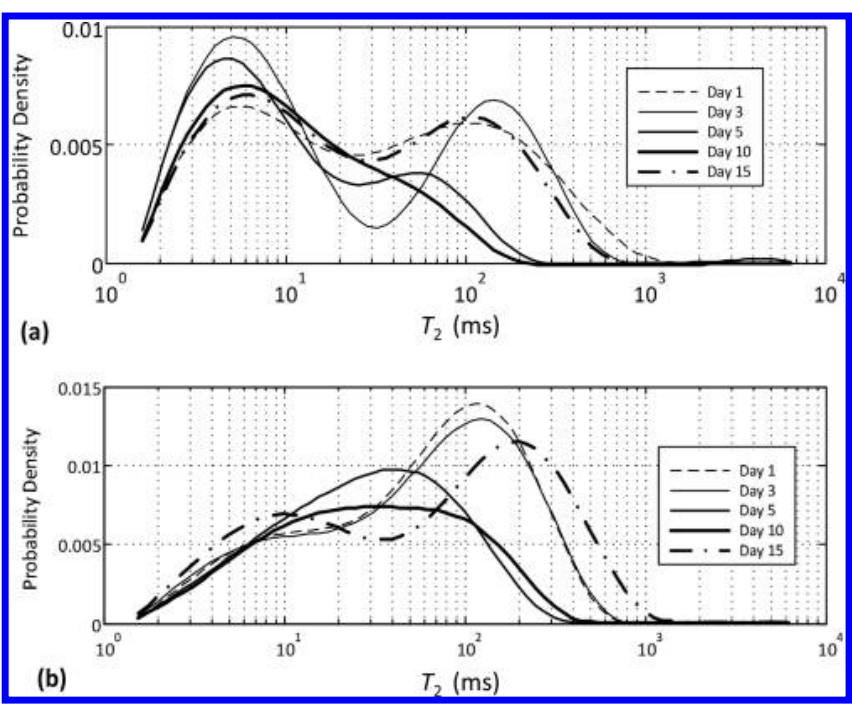

Figure 3. $T_{2}$ distribution for LF well (a) and HF well (b). The curves show the transition over time of the distribution of $T_{2}$ relaxation times in each well, beginning at inoculation (short dash line). As biofilm grew in the NMR probe's sensitive region, the $T_{2}$ relaxation times shifted to a single peak distribution centered about a shorter mean log $T_{2}$ time (solid lines). After each well was flushed and bleached, the $T_{2}$ relaxation distributions closely resembled the initial distributions (dash-dot lines).

As bacteria grow in the soil pores, the creation of gel phase EPS and the resulting exchange of hydrogen in the polymerized structure produces a secondary relaxation mechanism. ${ }^{21} \mathrm{We}$ attribute the collapsing the bimodal distribution to this mechanism, where the otherwise long relaxation time components shift to shorter relaxation times. In both wells, $T_{2}$ distributions measured Days 6-12 show a single peak, on the order of $10^{1} \mathrm{~ms}$. The transition to shorter relaxation times is an indication of biofilm accumulation. ${ }^{19,27,28}$ Data collected on Day 15 after flushing and bleaching each well shows a return to the bimodal $T_{2}$ distribution that typified the system prior to biofilm growth.

On Day 12, following 2 days of biofilm starvation, the two probes were raised from the well bottom to record $T_{2}$ relaxation over 3.0-3.5 m of saturated well depth in $0.5 \mathrm{~m}$ increments. In the HF well data set (Figure 2, triangles), the two data points collected on Day 12 show the difference in the measurements due to raising and replacing the probe in its original position. In the LF well data set, the Day 12 data point (Figure 2, squares) was measured prior to raising the probe. The measurement made after repositioning the probe at the bottom of the LF well was made on Day 14. For both data sets, the open marker represents the data collected after the probe was repositioned at the bottom of the well. The variance exists both because of inherent noise in the data and because the probe was likely exciting a slightly different shell within the soil where heterogeneities exist in both the soil and biofilm. The difference is $17 \%$ and $14 \%$, respectively, in the LF and HF wells and is significantly less than the change in signal response measured during the biofilm growth phase. The lower-value data points collected on Day 14 show that the biofilm surrounding both wells remained intact and relatively robust despite 4 days of starvation, compared to earlier measurements during the biofilm growth phase. This is consistent with the durability of the biobarrier originally constructed in the test cell where measured conductivity remained 2 orders of magnitude lower than the initial conductivity after approximately 6 months of starvation. ${ }^{7}$

The higher-value data points from each well on Day 14 were measured after a high-flow flush with groundwater from the test cell. The final data point, on Day 15, was collected after the wells were each treated with the same sodium dichlor solution used in the site preparation step to oxidize organics (Supporting Information). It was expected that the high shear stress and bleach solution in the soil pores would detach and remove most of the biofilm previously formed, causing the $T_{2}$ distribution to return to longer relaxation times.

When the test cell was constructed, coarser soil from an offsite location was used in the region where the HF well was located. The finer textured soil surrounding LF well was excavated on-site, sieved, and replaced. This variation in the soil texture between the two wells explains the differing magnitudes of the two relaxation peaks seen in the Day 1 and 15 data (Figure 3a,b), with relatively more of the pore space around the HF well composed of larger pores and a more even distribution of pores sizes near the LF well. It is likely that the soil mineralogy also differs between the two wells, though examination of such parameters was beyond the scope of this experiment.

More signal was recovered following removal in the HF well than in the LF well, likely due to the coarser soil and larger pores in the vicinity of the HF well. These larger pores would allow for bleach solution and detached EPS to be transported more easily through the excitation shell. In the soil around the LF well, bleach solution penetration may have occurred along preferential flow paths and biofilm sloughed from one pore may have been trapped in another smaller pore where it may have still contributed to the measured signal. Furthermore, the initial bleach injection was performed prior to installing the NMR probes, so the bleach was free to migrate up the casing and may 


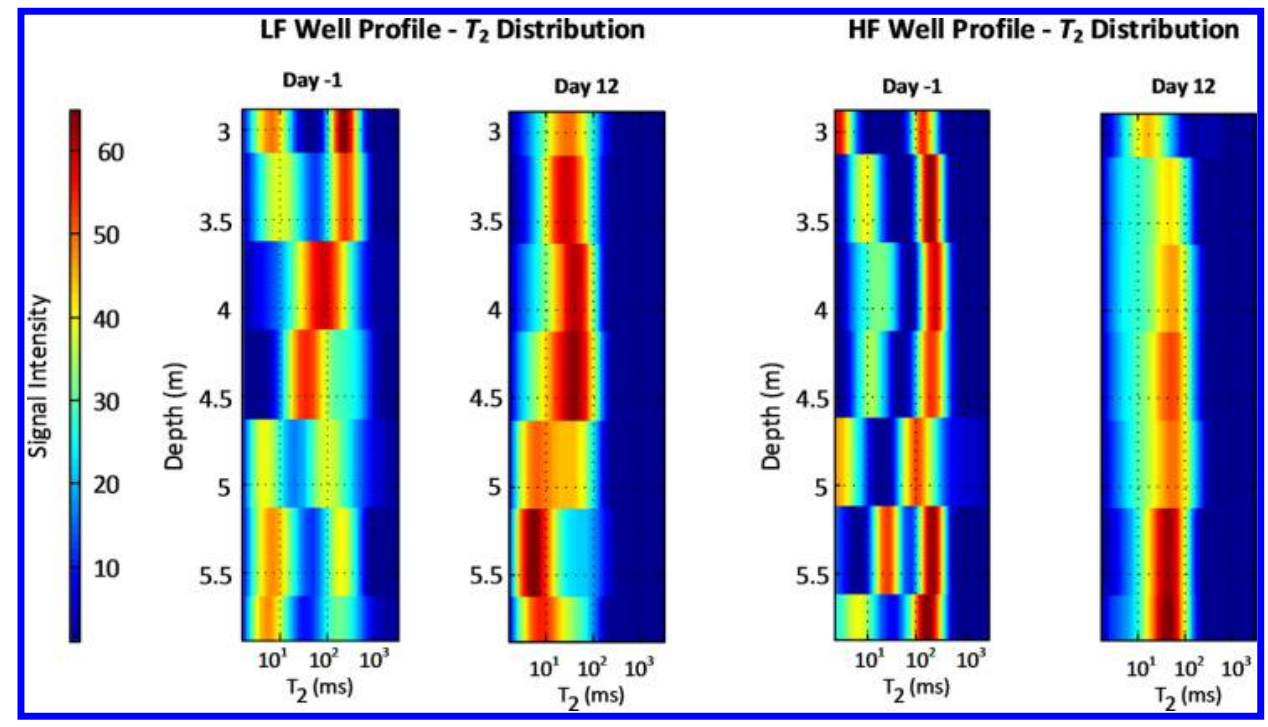

Figure 4. LF and HF well profiles measured Day -1 (preinoculation) and Day 12 of the biofilm growth phase. $T_{2}$ distribution as a function of depth shifted to faster decay times over the entire measured depth of each well when biofilm was cultivated at the well bottom.

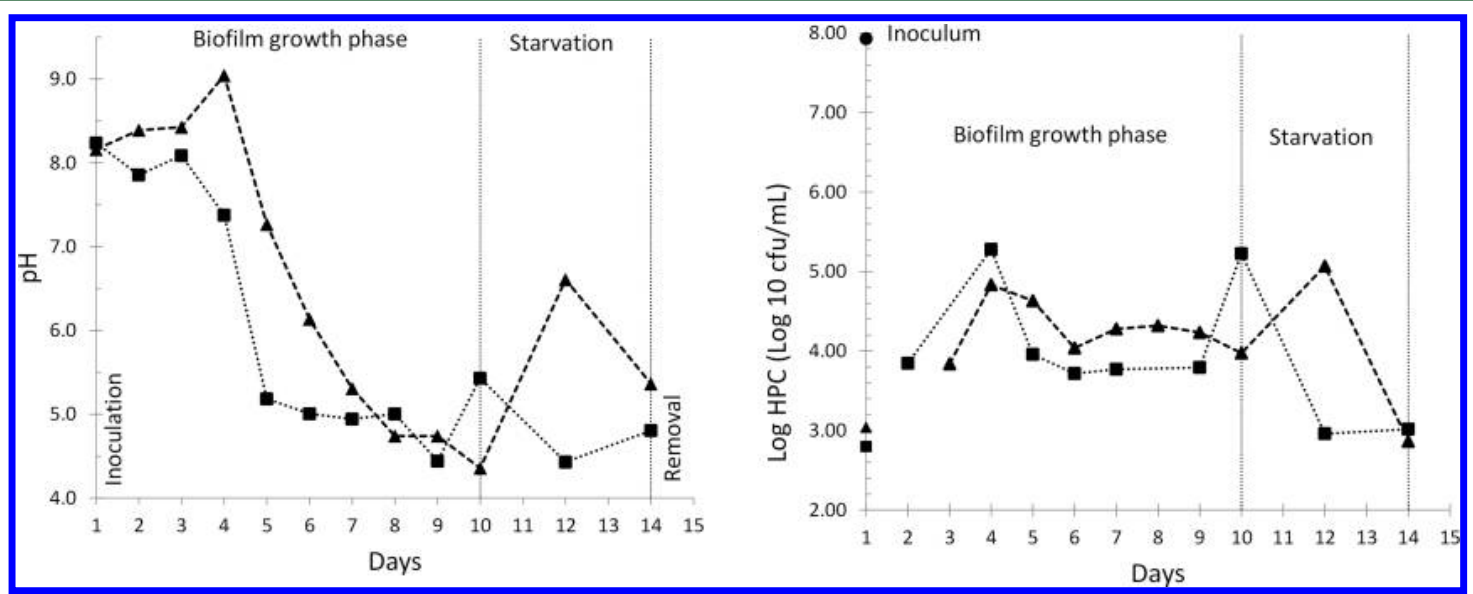

Figure 5. Heterotrophic plate counts (HPC) (a) and $\mathrm{pH}$ data (b). Both HPC and $\mathrm{pH}$ measurements decreased on Day 5 in the two wells compared to earlier values, with increased variability in the measurements noted during the starvation phase when no substrate was injected (LF well data is shown with square markers, HF well data with triangle markers). This water chemical variability was not reflected in the NMR signal response, which remained consistent over the same period.

not have penetrated the target area at design strength. The final bleach injection, which occurred with the probes in place and below the diversion disks, would have more effectively isolated the biofilm growth area. Some soil pores may have experienced the second bleach pulse but not the first. The measurements collected Days 14 and 15 confirm that the mechanism responsible for the change in $T_{2}$ relaxation could be reversed with flushing and bleaching the wells and is consistent with biofilm growth.

$T_{2}$ measurements were recorded with respect to depth in each well prior to inoculation and again on Day 12 (Figure 4). These well logs show notable differences. In both well logs, there was a change in $T_{2}$ distribution over the entire measured depth after 10 days of substrate injection at the bottom of the well where the NMR logging tool was deployed. On Day -1, the two well logs show broad $T_{2}$ distributions marked by two peaks at most depth levels. After the biofilm growth phase, the Day 12 data show a single peak distribution of $T_{2}$ relaxation times centered about a shorter mean relaxation time.

The observed changes in the well log are consistent with biofilm cultivation at the well bottom. The changes in the distributions are most pronounced at the bottom of the well, where the substrate was injected. The diversion disk attached to the top of each probe was located approximately in the middle of the distributions shown, meaning that substrate was directly accessible to the bottom half of each well log. As biofilm accumulated in the soil pores, the substrate would have encountered increased resistance to flow through the soil ${ }^{10}$ and the gap between the casing and the diversion disk $(\sim 1 \mathrm{~mm})$ would have become a preferential flow pathway. Substrate would diffuse into the soil above the probe, in addition to the substrate diffusing through the soil itself. Again the difference between the LF and HF well is instructive, as the upper levels of the HF well show less intensity of effect than the upper levels of the LF well. The HF well is surrounded by coarser soil, making it more difficult for the biofilm to clog the soil pores. Conversely, the LF well region had smaller soil pores initially and experienced more abundant biofilm accumulation as shown by the larger reduction in mean $\log T_{2}$ relaxation times. 


\section{MICROBIOLOGICAL DATA AND WATER CHEMICAL ANALYSIS}

Heterotrophic plate counts (HPC) in both wells were approximately $1 \times 10^{3}$ colony-forming units $(\mathrm{cfu}) / \mathrm{mL}$ after bleaching and prior to inoculation, representing the culturable "native" heterotrophic population of the test cell (Figure 5a). After inoculation and substrate injection, the HPC increased in both wells to approximately $1 \times 10^{5} \mathrm{cfu} / \mathrm{mL}$ by Day 4 . Prior to inoculation and following the injection of the sodium dichlor solution 2-3 days previously, $\mathrm{pH}$ measurements were approximately $\mathrm{pH} 8$ (Figure $5 \mathrm{~b}$ ). The $\mathrm{pH}$ in both wells was stable through Day 3 following inoculation. On Day 4, the $\mathrm{pH}$ measurements diverged with the $\mathrm{HF}$ well $\mathrm{pH}$ increasing to $\mathrm{pH}$ 9, while the LF well $\mathrm{pH}$ decreased to approximately $\mathrm{pH} 7$. Also on Day 4, the NMR signal in both wells changed significantly, dropping to near the minimum for mean $\log T_{2}$ relaxation time in the LF well where the effect was more pronounced (Figure 3). Taken together, the higher HPC values, optimum $\mathrm{pH}$ conditions, and faster NMR signal decay indicate that a measurable accumulation of biofilm had grown within the pore spaces of the logging tool's sensitive zone by Day 4 of the experiment. Because the HPC reflect bacterial cells which are necessarily not attached in biofilms, the NMR logging tool indicates itself as a valuable addition to the bioremediation toolbox through its sensitivity to the biofilm EPS, which is not measurable with plate counts.

Water samples from Days 5-10 of the experiment show a decrease in HPC to approximately $1 \times 10^{4} \mathrm{cfu} / \mathrm{mL}$ and a decrease in $\mathrm{pH}$ to approximately $4.5-5$ in both wells. Lower $\mathrm{pH}$ promotes bacterial attachment to surfaces, ${ }^{29}$ while not significantly adversely affecting the biofilm matrix over the relatively short time frame measured. ${ }^{30}$ This increased adhesion of bacteria may have reduced the number of suspended cells within the bulk fluid for capture during sampling or caused preferential sampling of the well casing fluid, rather than pore water, due to biofilm clogging the soil pores. It is also possible that the acidic conditions selected for other native bacterial strains that are not culturable on agar plates, like autolithotrophs participating in oxidation and reduction of chemical species in the soil and water.

To explore potential causes for the observed drop in $\mathrm{pH}$ during testing, benchtop tests were performed using isolates of the two most populous cell morphologies from the agar plates for Days 5-10. These bacteria were cultivated in $100 \mathrm{~mL}$ of molasses substrate in Erlenmeyer flasks. The $\mathrm{pH}$ of the broth decreased by more than 1 order of magnitude, from $\mathrm{pH} 6.2$ on average to $\mathrm{pH} 5.0$ on average by Day 4 of the 8 day benchtop experiment. These results are consistent with results from the field study and indicate that metabolic processes, including production of nucleic acids and $\mathrm{CO}_{2}$, contributed to the observed decrease in $\mathrm{pH}$ observed in the field study.

Another possible explanation of the observed $\mathrm{pH}$ change is related to the redox chemistry of sulfur and iron cycling. ${ }^{31,32}$ The groundwater in the lined test cell was static for more than 10 years before the current field study was initiated, creating reducing conditions at the bottom of the test cell. The distinctive odor of hydrogen sulfide $\left(\mathrm{H}_{2} \mathrm{~S}\right)$ was readily perceptible in the water pumped from the cell. When exposed to the atmosphere, the reduced $\mathrm{Fe}$ (II) in the groundwater oxidized to form a rust-like layer of $\mathrm{Fe}$ (III) compounds, likely ferrihydrite, in the large-capacity water storage tanks. The injection of the sodium dichlor solution followed by substrate containing organic carbon, nitrate, and dissolved oxygen would have promoted the oxidation of reduced species in the subsurface. Heterotrophic bacteria, like Pseudomonas fluorescens, use the electron acceptors oxygen and nitrate to oxidize the organic carbon in the media, producing new cells, EPS, and waste products. Oxidation of sulfide leads to acidification, as in the case of acid mine drainage, ${ }^{33}$ and may account for some of the observed decrease in $\mathrm{pH}$ after the initial biofilm growth between Days 1 and 4 .

Laboratory studies have shown that NMR relaxation measurements are sensitive to changing soil redox conditions ${ }^{34}$ as well as the mineralogic form of iron species. ${ }^{35,36}$ To conclude that the observed changes in relaxation response are due to biofilm growth, it is important, therefore, to consider the possible impact of geochemical changes. First, the timing of the changes is indicative of biofilm growth. Were oxidation-driven geochemical changes strongly influencing $T_{2}$ during the approximately 2 days between the initial bleach and inoculation, we would expect to see significant changes in the $T_{2}$ relaxation behavior of the two well systems Days -1 and 0 . Instead, we see relatively small changes: first a slight decrease in $T_{2}$ which may, in fact, be due to abiotic Fe(III) precipitation, then an increase during inoculum injection (Figure 2). The increase is most likely due to the makeup of the inoculum broth which was made with DI water rather than water from the test cell. The tight temporal relationship at the end of the experiment between the final flush and bleach and the observed recovery of long $T_{2}$ times provides further strong evidence that the oxidizing conditions themselves do not drive the shortening of the $T_{2}$ response.

A second reason we expect limited influence from mineralogical transformations pertains to competition for the electron acceptors in the subsurface. The 4 log reduction between the inoculum colony count and the Day 2 HPC (Figure 5a) indicates approximately $10^{4}$ colony forming units $(\mathrm{cfu}) / \mathrm{mL}$ attached to soil surfaces in the well-bore, creating strong competition for oxygen and nitrate. Oxidation of the $\mathrm{H}_{2} \mathrm{~S}$ would have been more thermodynamically favorable compared to oxidation of iron compounds and would have occurred preferentially ${ }^{37}$ where the electron acceptors available exceeded bacterial demand. We therefore expect the contribution of iron precipitation to be moderated and would not expect the iron-driven $T_{2}$ changes to be any larger than was observed in the small decrease between Days -1 and 0 before competing heterotrophic bacteria were present in the system.

Finally, we have also considered the magnitude of the observed $T_{2}$ shortening to assess whether biofilm growth or moderate changes in iron geochemistry are more likely mechanisms. The $T_{2}$ shortening observed during the experiment generally shows long components, $T_{2} \gg 100 \mathrm{~ms}$, transitioning to shorter relaxation time components, $T_{2} \ll 100$ ms. Thus, the dominant relaxation mechanism(s) must be ones that can result in $T_{2}$ relaxation times much shorter than $100 \mathrm{~ms}$.

With the exception of magnetite and hematite, the literature reports elevated, but moderate surface relaxivity for most $\mathrm{Fe}(\mathrm{III})$ minerals at a measurement frequency of $2 \mathrm{MHz}{ }^{35}$ Large reductions in relaxation times resulting from the change of $\mathrm{Fe}$ (II) to $\mathrm{Fe}$ (III) have been shown at $90 \mathrm{MHz},{ }^{34}$ but this measurement frequency is more than 100 times higher than the current downhole measurements. Relaxation times exhibit significant and complex frequency dependence over this wide range. Generally, the geochemical changes are expected to show a reduced influence on $T_{2}$ at lower field strengths ${ }^{38}$ since the 
amplitude of internal gradients associated with diffusion relaxation are reduced at lower field.

With evidence suggesting moderate ferrihydrite formation is unlikely to cause the absolute $T_{2}$ shortening we observe, we consider evidence of $T_{2}$ shortening due to the mechanism of biofilm polymerization. Laboratory measurements at $275 \mathrm{kHz}$ by Sanderlin et al. (2012) showed growth of biofilm and polymer gels resulted in $T_{2}$ values as short as $50 \mathrm{~ms}^{21}$ Furthermore, in previous laboratory work using the same LF probe ${ }^{20}$ moderate biofilm growth in $1 \mathrm{~mm}$ quartz sand resulted in a decrease in the mean $\log T_{2}$ of $45 \%$ which is similar in magnitude to the changes observed in this study.

Geochemical changes in the pore fluid would have occurred slowly over the two week period, and the drop in $T_{2}$ would be expected to be considerably less than was observed. Given the timing and magnitude of the $T_{2}$ changes, and the evidence from previous lab work that biofilm has a large influence on NMR relaxation measurements, the experimental results provide compelling evidence that the low field NMR logging tools can detect and monitor biofilm growth in the subsurface. How biofilms interact with the geochemical environment will vary from field site to field site, as well as over space and time. Future experiments and implementation of these methods, therefore, should include an informed monitoring of the chemistry of extracted pore fluid and the changing NMR relaxation.

We have shown the NMR logging tools detected significant and sustained change in signal response during the biofilm growth phase, measured by changing $T_{2}$ relaxation distributions. Both the HF and LF probes were sensitive to the changes, and the differences in soil geology between the probe locations likely resulted in larger differences in the signal response than the variation between the two probes. Mean log $T_{2}$ relaxation times decreased from $29 \mathrm{~ms}$ to an average of 11 $\mathrm{ms}$ in the LF well, and from $50 \mathrm{~ms}$ to an average of $28 \mathrm{~ms}$ in the HF well while biofilm was cultivated in the surrounding soil. We have further shown that high shear flow and oxidative stress resulting from the bleach solution, applied with the intent to denature and remove biofilm from the tool's sensitive zone, produced a return of signal response similar to initial conditions. The time scale of these changes is consistent with biofilm formation and subsequent removal. These results provide an important demonstration of the advantages of incorporating an NMR measurement into future bioremediation toolkits. NMR $T_{2}$ relaxation measurements provide unique complementary data that, together with other monitoring techniques such as hydrological conductivity measurements, can improve our ability to draw the correct conclusion about the subsurface environment with regard to biofilm growth.

\section{ASSOCIATED CONTENT}

\section{S Supporting Information}

The Supporting Information is available free of charge on the ACS Publications website at DOI: 10.1021/acs.est.5b02690.

Detailed methods descriptions, additional results and discussion (PDF).

\section{AUTHOR INFORMATION}

\section{Corresponding Author}

*S. L. Codd. Tel.: (406) 994-1944. Fax: (406) 994-6292. Email: scodd@coe.montana.edu.

\section{Notes}

The authors declare no competing financial interest.

\section{ACKNOWLEDGMENTS}

This material is based upon work supported, in part, by the US Department of Energy, Office of Science under Award DESC0006376. Any opinions, findings, and conclusions or recommendations expressed in this material are those of the author(s) and do not necessarily reflect the views of the Department of Energy. This material is based upon work supported by the National Science Foundation Graduate Research Fellowship Program under Grant No. DGE1049562. Authors gratefully thank the German Carl-Zeiss Foundation and the Karlsruhe House of Young Scientists (KHYS) for their financial support. The authors also thank Drs. Adrienne Phillips and Lisa Kirk at the Center for Biofilm Engineering, and Steve Antonioli and staff at MSE Technology Applications in Butte, Montana.

\section{REFERENCES}

(1) LaGrega, M. D.; Buckingham, P. L.; Evans, J. C. Hazardous Waste Management, 2nd ed.; McGraw-Hill: New York, 2001.

(2) Kao, C. M.; Chen, K. F.; Chen, Y. L.; Chen, T. Y.; Huang, W. Y. Biobarrier system for remediation of TCE-contaminated aquifers. Bull. Environ. Contam. Toxicol. 2004, 72 (1), 87-93.

(3) Kao, C. M.; Chen, Y. L.; Chen, S. C.; Yeh, T. Y.; Wu, W. S. Enhanced PCE dechlorination by biobarrier systems under different redox conditions. Water Res. 2003, 37 (20), 4885-4894.

(4) Kim, G.; Lee, S.; Kim, Y. Subsurface biobarrier formation by microorganism injection for contaminant plume control. I. Biosci. Bioeng. 2006, 101 (2), 142-148.

(5) Pal, A.; Paul, A. K. Microbial extracellular polymeric substances: central elements in heavy metal bioremediation. Indian I. Microbiol. 2008, 48 (1), 49-64.

(6) Taylor, S. W.; Jaffe, P. R. Enhanced in-situ biodegradation and aquifer permeability reduction. I. Environ. Eng. (Reston, VA, U. S.) 1991, 117 (1), 25-46.

(7) Cunningham, A. B.; Sharp, R. R.; Hiebert, R.; James, G. Subsurface biofilm barriers for the containment and remediation of contaminated groundwater. Biorem. I. 2003, 7 (3-4), 151-164.

(8) Careghini, A.; Saponaro, S.; Sezenna, E. Biobarriers for groundwater treatment: a review. Water Sci. Technol. 2012, 67 (3), 453-468.

(9) Callaghan, P. T. Translational Dvnamics \& Magnetic Resonance: Principles of Pulsed Gradient Spin Echo NMR Oxford University Press: New York, 2011.

(10) Cunningham, A. B.; Characklis, W. G.; Abedeen, F.; Crawford, D. Influence of biofilm accumulation on porous-media hydrodynamics. Environ. Sci. Technol. 1991, 25 (7), 1305-1311.

(11) Taylor, S. W.; Jaffe, P. R. Biofilm growth and the related changes in the physical properties of a porous medium. 1. Experimental investigation. Water Resour. Res. 1990, 26 (9), 2153-2159.

(12) Vandevivere, P.; Baveye, P. Effect of bacterial extracellular polymers on the saturated hydraulic conductivity of sand columns. Appl. Environ. Microbiol. 1992, 58 (5), 1690-1698.

(13) Mobile NMR and MRI: Developments and Applications; Johns, M., Fridjonsson, E., Vogt, S., Haber, A., Eds.; Royal Society of Chemistry: London, 2015.

(14) Walsh, D.; Turner, P.; Grunewald, E.; Zhang, H.; Butler, J. J.; Reboulet, E.; Knobbe, S.; Christy, T.; Lane, J. W.; Johnson, C. D.; Munday, T.; Fitzpatrick, A. A small-diameter NMR logging tool for groundwater investigations. Groundwater 2013, 51 (6), 914-926.

(15) Kleinberg, R. L.; Kenyon, W. E.; Mitra, P. P. Mechanism of NMR relaxation of fluids in rock. L.Magn. Reson. Ser. A 1994, 108, 206-214. 
(16) Kleinberg, R. L.; Horsfield, M. A. Transverse relaxation processes in porous sedimentary rock. J. Magn. Reson. 1990, 88 (1), 9-19.

(17) Timur, A. Pulsed nuclear magnetic resonance studies of porosity, movable fluid, and permeability of sandstones. JPT, $\underline{\text {. Pet. }}$ Technol. 1969, 21 (06), 775-786.

(18) Godefroy, S.; Korb, J. P.; Fleury, M.; Bryant, R. G. Surface nuclear magnetic relaxation and dynamics of water and oil in macroporous media. Phys. Rev. E 2001, 64 (2), 021605-1-02160513.

(19) Codd, S. L.; Vogt, S. J.; Hornemann, J. A.; Phillips, A. J.; Maneval, J. E.; Romanenko, K. R.; Hansen, L.; Cunningham, A. B.; Seymour, J. D. NMR relaxation measurements of biofouling in model and geological porous media. Org. Geochem. 2011, 42 (8), 965-971.

(20) Kirkland, C. M.; Hiebert, R.; Phillips, A.; Grunewald, E.; Walsh, D. O.; Seymour, J. D.; Codd, S. L. Biofilm Detection in a Model WellBore Environment Using Low-Field NMR. Groundwater Monitor. Rem. 2015, DOI: $10.1111 /$ gwmr.12117.

(21) Sanderlin, A. B.; Vogt, S. J.; Grunewald, E.; Bergin, B. A.; Codd, S. L. Biofilm detection in natural unconsolidated porous media using a low-field magnetic resonance system. Environ. Sci. Technol. 2013, 47 (2), 987-992.

(22) Vogt, S. J.; Sanderlin, A. B.; Seymour, J. D.; Codd, S. L. Permeability of a growing biofilm in a porous media fluid flow analyzed by magnetic resonance displacement-relaxation correlations. Biotechnol. Bioeng. 2013, 110 (5), 1366-1375.

(23) Herigstad, B.; Hamilton, M.; Heersink, J. How to optimize the drop plate method for enumerating bacteria. I. Microbiol. Methods 2001, 44 (2), 121-129.

(24) Carr, H. Y.; Purcell, E. M. Effects of diffusion on free precession in nuclear magnetic resonance experiments. Phvs. Rev. 1954, 94 (3), 630-638.

(25) Meiboom, S.; Gill, D. Modified spin-echo method for measuring nuclear relaxation times. Rev. Sci. Instrum. 1958, 29 (8), 688-691.

(26) Korb, J. P.; Godefroy, S.; Fleury, M. Surface nuclear magnetic relaxation and dynamics of water and oil in granular packings and rocks. Magn. Reson. Imaging 2003, 21 (3-4), 193-199.

(27) Bayer, J. V.; Jaeger, F.; Schaumann, G. E. Proton Nuclear Magnetic Resonance (NMR) Relaxometry in Soil Science Applications. Open Magn. Reson. I. 2010, 3, 15-26.

(28) Jaeger, F.; Grohmann, E.; Schaumann, G. E. 1H NMR relaxometry in natural humous soil samples: insights in microbial effects on relaxation time distributions. Plant Soil 2006, 280 (1-2), 209-222.

(29) Kristian Stevik, T.; Kari, A.; Ausland, G.; Fredrik Hanssen, J. Retention and removal of pathogenic bacteria in wastewater percolating through porous media: a review. Water Res. 2004, 38 (6), 1355-1367.

(30) Chen, M. J.; Zhang, Z.; Bott, T. R. Effects of operating conditions on the adhesive strength of Pseudomonas fluorescens biofilms in tubes. Colloids Surf. B 2005, 43 (2), 61-71.

(31) Juncher Jørgensen, C.; Jacobsen, O. S.; Elberling, B.; Aamand, J. Microbial Oxidation of Pyrite Coupled to Nitrate Reduction in Anoxic Groundwater Sediment. Environ. Sci. Technol. 2009, 43 (13), 48514857.

(32) Melton, E. D.; Swanner, E. D.; Behrens, S.; Schmidt, C.; Kappler, A. The interplay of microbially mediated and abiotic reactions in the biogeochemical Fe cycle. Nat. Rev. Microbiol. 2014, 12 (12), 797-808.

(33) Evangelou, V. P.; Zhang, Y. L. A review: Pyrite oxidation mechanisms and acid mine drainage prevention. Crit. Rev. Environ. Sci. Technol. 1995, 25 (2), 141-199.

(34) Bryar, T. R.; Knight, R. J. Sensitivity of nuclear magnetic resonance relaxation measurements to changing soil redox conditions. Geophys. Res. Lett. 2002, 29 (24), DOI: 10.1029/2002GL016043.

(35) Keating, K.; Knight, R. A laboratory study to determine the effect of iron oxides on proton NMR measurements. Geophysics 2007, 72 (1), E27-E32.
(36) Keating, K.; Knight, R. A laboratory study of the effect of Fe(II)bearing minerals on nuclear magnetic resonance (NMR) relaxation measurements. Geophvsics 2010, 75 (3), F71-F82.

(37) Benjamin, M. M. Water Chemistry; McGraw-Hill: New York, 2002.

(38) Koenig, S. H.; Kellar, K. E. Theory of $1 / \mathrm{T}-1$ and 1/T-2 NMRD profiles of solutions of magnetic nanoparticles. Magn. Reson. Med. 1995, 34 (2), 227-233. 